\title{
A construção da corporeidade travesti no Brasil e seu acesso à saúde: revisão integrativa.
}

\author{
Nathália Ferreira Santos Tosti, Nubya S. Anzolin, Leonardo Jayme C. Rocha, Dalvani Marques.
}

\section{Resumo}

Este estudo objetiva identificar a construção da corporeidade travesti na literatura e delimitar aspectos dessa construção que influenciam em seu acesso à saúde. Método: Revisão integrativa da literatura. A coleta de dados ocorreu nas bases de dados PubMed, LILACS e BVS, utilizando os descritores "pessoas transgênero", "travestismo", "procedimentos de readequação sexual" e "saúde das minorias", como critério de inclusão consideraram-se artigos publicados entre 2009 a 2018 nos idiomas português, inglês e espanhol e que respondiam à pergunta norteadora da pesquisa. A análise dos artigos se deu através da Análise de Conteúdo. Resultados: Selecionados 23 artigos, delineando três categorias: acesso à saúde, corpo e corporeidade travesti e construção e incorporação social da travestilidade. Conclusões: Evidencia-se que particularidades da construção social e corporal travesti estão associadas a adoção de comportamentos de risco e afastamento dos serviços de saúde. Há necessidade de reconstruir os itinerários terapêuticos dessa população para trazê-las ao serviço de saúde, bem como treinamento dos profissionais para superação de preconcepções e garantia de equidade no tratamento.

\section{Palavras-chave:}

Pessoas transgênero, travestismo, saúde das minorias.

\section{Introdução}

No Brasil, a saúde é direito de todos e dever do Estado e deve ser proporcionada por políticas sociais e econômicas em busca da garantia do acesso universal e igualitário aos serviços de saúde. Em paralelo, reconhece-se a existência de grupos socialmente vulneráveis no país, entre eles a população travesti, indivíduos repreendidos socialmente devido a transgressão do binarismo de gênero. A travesti vivencia a feminilidade em corpos masculinos fabricando um novo sujeito, dificultando assim seu acesso aos serviços de saúde. Logo, a identificação de fatores associados às travestilidades que exercem influência no acesso à saúde dessa população é uma ferramenta para criação de intervenções que possam reequilibrar o processo saúde-doença e favorecer o acesso ${ }^{(1,2)}$.

Objetivos: Identificar a construção da corporeidade da travesti na literatura científica; Delimitar aspectos da construção corporal travesti que influenciam em seu acesso à saúde.

\section{Resultados e Discussão}

Selecionados 23 artigos cujos resultados traçaram três diferentes categorias (Tabela 1):

Tabela 1. Descrição das categorias, Campinas, 2019.

\begin{tabular}{|c|c|c|}
\hline Categoria & Descrição & Total \\
\hline $\begin{array}{l}\text { Acesso } \\
\text { saúde }\end{array}$ & $\begin{array}{l}\text { Aborda questões sobre as } \\
\text { discriminações vividas em serviços } \\
\text { de saúde e a necessidade } \\
\text { vivenciada pelos profissionais de se } \\
\text { adaptarem para incluírem } \\
\text { populações socialmente vulneráveis } \\
\text { como a de travestis em sua prática. }\end{array}$ & 14 \\
\hline $\begin{array}{l}\text { Corpo e } \\
\text { corporeidade } \\
\text { travesti }\end{array}$ & $\begin{array}{l}\text { Apresenta reflexões sobre } \\
\text { necessidades de modificação } \\
\text { corporal vividas por esse púbico e } \\
\text { os significados atribuídos a estes } \\
\text { processos. }\end{array}$ & 3 \\
\hline $\begin{array}{l}\text { Construção } \\
\text { e } \\
\text { incorporação } \\
\text { social da } \\
\text { travestilidade }\end{array}$ & $\begin{array}{l}\text { Identifica as influências do meio } \\
\text { social em que a travesti é } \\
\text { construída, bem como busca } \\
\text { compreender as tensões binárias } \\
\text { que constroem o sujeito e sua } \\
\text { representação no feminino. }\end{array}$ & 7 \\
\hline
\end{tabular}

É possível identificar uma correlação entre as categorias que muitas vezes dialogavam em uma relação causaconsequência. Assim, nota-se que questões referentes a construção e incorporação social da travestilidade se associam a condições vivenciadas devido às necessidades de modificação corporal do sujeito e construção de um corpo social próprio.

Essas questões, quando comparadas pela literatura, são fatores causais para as principais dificuldades encontradas no acesso à saúde dessa população em conjunto com o despreparo dos serviços e profissionais de saúde em lidar com as particularidades do grupo estudado.

\section{Conclusões}

A análise dos artigos evidencia que as particularidades da construção corporal travesti, como o uso de silicone líquido industrial, hormonização, violência e exclusão, prostituição, dor, rivalidade e amizade, constituem a quebra das expectativas sociais heteronormativas. As barreiras existentes entre profissionais de saúde, geradas por preconcepções da travestilidade, os impedem de se aprofundar em questões necessárias para identificar a construção da identidade travesti como uma influência contínua do meio social discriminatório. Dessa forma, a travesti passa a evitar os serviços de saúde temendo o preconceito e a violência institucional, sendo assim, os profissionais de saúde devem especializar o cuidado prestado para as particularidades encontradas, além da questão HIV/aids. Esse processo deve representar a incorporação dos serviços formais de saúde aos itinerários terapêuticos das travestis.

\section{Agradecimentos}

Agradecimentos ao PIBIC/CNPq pelo fomento através da bolsa de Iniciação Científica.

\footnotetext{
${ }^{1}$ Sanchez RM, Ciconelli RM. Conceitos de acesso à saúde. Rev Panam Salud Publica. 2012; 31(3): 260-8

${ }^{2}$ Amorim SMG, Vieira FS, Brancaleoni AP. Percepções acerca da condição de vida e vulnerabilidade à saúde de travestis. Saúde Debate. 2013; 37(98): 525 35 .
} 